\title{
Postoperative Analgesic Efficacy of Tramadol and Diclofenac Sodium in Goats
}

\author{
${ }^{1}$ Buhari, S., ${ }^{2}$ Amaje, J., ${ }^{3}$ Bello, Z. M., ${ }^{3}$ Ahmad, S., ${ }^{1}$ Abubakar, N., ${ }^{1}$ Bodinga, H. A. and ${ }^{4}$ Sani, \\ M. I.
}

\begin{abstract}
${ }^{1}$ Department of Veterinary Surgery and Radiology, Faculty of Veterinary Medicine, Usmanu Danfodiyo University Sokoto, Nigeria ${ }^{2}$ Military Veterinary Clinic, Nigerian Defence Academy, Kaduna, Nigeria

${ }^{3}$ Ministry of Animal Health, Husbandry and Fisheries, Kebbi State Zonal Veterinary Clinic, Birnin Kebbi, Kebbi State, Nigeria.

${ }^{4}$ Department of Veterinary Pharmacology and Toxicology, Faculty of Veterinary Medicine, Usmanu Danfodiyo University Sokoto, Nigeria
\end{abstract}

*Author for Correspondence: msbuhari7@gmail.com

\begin{abstract}
Postoperative analgesic effects of tramadol and diclofenac in goats presented for diaphyseal femoral fracture management were compared. Eight adult goats aged 10 to 24 months (16 \pm 5.2 months) were used. The first group of 4 goats received $3 \mathrm{mg} / \mathrm{kg}$ of tramadol intramuscularly (IM), and $2.5 \mathrm{mg} / \mathrm{kg}$ of diclofenac sodium was administered to the second group of 4 goats before induction of anesthesia IM. Mechanical pain scores, clinico-physiological and red and white blood cell counts were evaluated over a period of twelve hours post drug administration. The study groups were not revealed to the postoperative pain assessors until the end of the study. There was no significant difference in the rectal temperature values and the analgesiometer readings between the tramadol and diclofenac groups $(\mathrm{p}<0.05)$. The variations in the pulse rate, respiratory rate, red and white blood cell counts between the groups fluctuated within the normal physiological limits. It was therefore concluded that preoperative intramuscular administration of tramadol at $3 \mathrm{mg} / \mathrm{kg}$ provided similar effective postoperative analgesia with diclofenac at 2.5 $\mathrm{mg} / \mathrm{kg}$ IM following femoral diaphyseal fracture management in goats.
\end{abstract}

Keywords: Analgesia; Diclofenac; Fracture Goats; Tramadol

\section{INTRODUCTION}

Postsurgical pain is considered beneficial to animals because body activities are slowed thereby preventing more injury to the surgical site (Hellyer et al., 2007). Recognition of pain in human is a subjective experience, but its nature in animals can be challenging since many animals have evolved to hide signs of illnesses and pain (Souza et al., 2008). Hence, the perception of pain is thought to be minimal and insignificant, and consequently neglected in ruminants (Hellyer et al., 2007). Improper management of post-operative pain can result to chronic pain, cardiorespiratory depression (Mastrocinque and Fantoni, 2003) and delayed wound healing (Lascelles et al., 1999; Buvanendranet al., 2003). In addition, pain following surgical procedure such as fracture reduction-fixation, suppresses the immune system of a patient and must be properly managed (Pollock et al., 1991). Fractures involving femoral diaphysis are frequently reported in goats that are left to scavenge for food in the environment. This system of management predisposes them to automobile accident or being hurled with hard objects, resulting into fractures (Witmer, 2016). Therefore, preemptive analgesia to prevent central and peripheral sensitization caused by incisional and inflammatory injuries is essential for effective postoperative pain management (Katz et al., 1992; Kissin, 2000). Both opioids and nonsteroidal anti-inflammatory drugs (NSAIDS) are the most frequently used drugs for the management of postoperative pain (Lee, 2011). Nonsteroidal anti-inflammatory drugs have been successfully used in veterinary practice for the management of postoperative pain.

Diclofenac sodium is among the frequently use NSAIDs in veterinary practice (Booth, 2001; Lascelles and Mair, 2001), its harmful side effects such as the gastrointestinal discomfort, cardiopulmonary depression (Elghazali et al., 2008) and inhibition of antibody production (Bancos et al., 2009) limits its use. Most opioid have been shown to be effective analgesics in the clinical setting in dogs (Waterman and Kalthum, 1989), albeit with a short duration of action. Opioids also produced a reversible behavioral (KuKanich et al., 2008) and physiological (Wagner, 2002) side effects such as respiratory depression and constipation. Tramadol is an analgesic with a dual mechanism of action where it is found to bind to the $\mu_{1}$-opioid receptor (Kukanich and Papich, 2004; Guedes et al., 2005) as well as inhibit the monaminergic pathway (McMillan et al., 2008). Due to this reason, tramadol is also referred to as an "atypical opioid" (McMillan et al., 2008). The aim of the study was to compare the postoperative analgesic effects of tramadol and diclofenac in goats following femoral fracture reduction-fixation. 


\section{MATERIALS AND METHODS}

Eight client-owned goats undergoing femoral diaphyseal fracture reduction-fixation at the Veterinary Teaching Hospital of Usmanu Danfodiyo University Sokoto, Nigeria were used for the study after obtaining verbal consent. Ages of the goats ranged from 10 to 24 months with a (mean \pm SD) of $16 \pm 5.2$ months. The body weight of the goats ranged from $12 \mathrm{~kg}$ to $17.5 \mathrm{~kg}$ with a (mean $\pm \mathrm{SD})$ of $14.1 \pm 1.8 \mathrm{~kg}$. All animals were clinically evaluated and were classified according to the American Society of Anesthesiologists scale (ASA 1 to 5). Only goats within ASA 1 to ASA 3 scales were included in the study (Ortega and Cruz, 2011). In addition, goats with open fracture were not included in the study. They were denied feed for 12 hours and water for 2 hours before the surgery. The goats were randomly divided into two groups of four animals each. Group I was treated with tramadol (Tramadol ${ }^{\circledR}$, Ozone Laboratories Group, Romania) at $3 \mathrm{mg} / \mathrm{kg}$ intramuscularly (IM) and group II received diclofenac sodium (Fitking Diclofena ${ }^{\circledR}$ inj, Jiangsu Huayang Pharmaceutical Co., Ltd. Siyang County Jiangsu, China) at $2.5 \mathrm{mg} / \mathrm{kg}$ IM before induction of anesthesia. A ketaminexylazine combination (ketamine $5 \mathrm{mg} / \mathrm{kg}$ and xylazine $0.1 \mathrm{mg} / \mathrm{kg}$ ) was administered intravenously to achieve general anaesthesia, and normal saline $(0.9 \% \mathrm{NaCl})$ (Braun Medical, Romania) was infused IV $(10 \mathrm{~mL} / \mathrm{kg} / \mathrm{h})$ throughout the surgical procedure. Pulse rate, respiratory rate and rectal temperature, red and white blood cell changes were the physiologic parameters used as indicators of acute pain (Buhari et al., 2012; Tesfaye et al., 2017). Above parameters were taken before drug administration $(0 \mathrm{hr})$ and hourly for 12 hours post-fracture reduction. Similarly, mechanical pain threshold was evaluated using analgesiometer (PainTest ${ }^{\mathrm{TM}}$ FPX 25 Algometer, Wagner Instruments, Greenwich, USA) for post-surgical analgesia (Reid et al., 2007). The device has been described as a reliable measure of pain in muscle, joints, tendons, and ligaments for experimental use in animal and humans (Moak et al., 2010; Buhagiar et al., 2011). The FPX 25 acts as a mechanical stimulus by applying increasing pressure until a response is noted proves the benefits of applied medication (Haussler et al., 2007). The analgesiometer FPX 25, used for pain threshold testing, is appropriate for determining the minimum pressure that triggers pain at the point of interest (Polianskis et al., 2002). The device was applied at four different areas $2 \mathrm{~cm}$ away from the site of incision (cranially, caudally, proximally, and distally). Maximum reading was set at $15 \mathrm{~N}$ to avoid trauma to the area. The assessment was conducted before drug administration $(0 \mathrm{hr})$ and hourly for 12 hours post-fracture reduction.

\section{Statistical Analyses}

Data were recorded as mean $\pm \mathrm{SD}$. A Kolmogorov-Smirnovtest was performed to assess normality of the variables. The data were analyzed using repeated measure of ANOVA. Significant differences $(\mathrm{p}<0.05)$ were further assessed by using Least Significant Difference (LSD) post hoc test (IBM SPSS software, ver. 16 for Windows; IBM, New York, USA). A $\mathrm{P}$ value $<0.05$ was considered statistically significant.

\section{RESULTS}

There was no significant difference $(p<0.05)$ between the groups treated with tramadol and diclofenac with regard to the rectal temperature and the analgesiometer pain thresholds in goats (Figures 1 and 2).

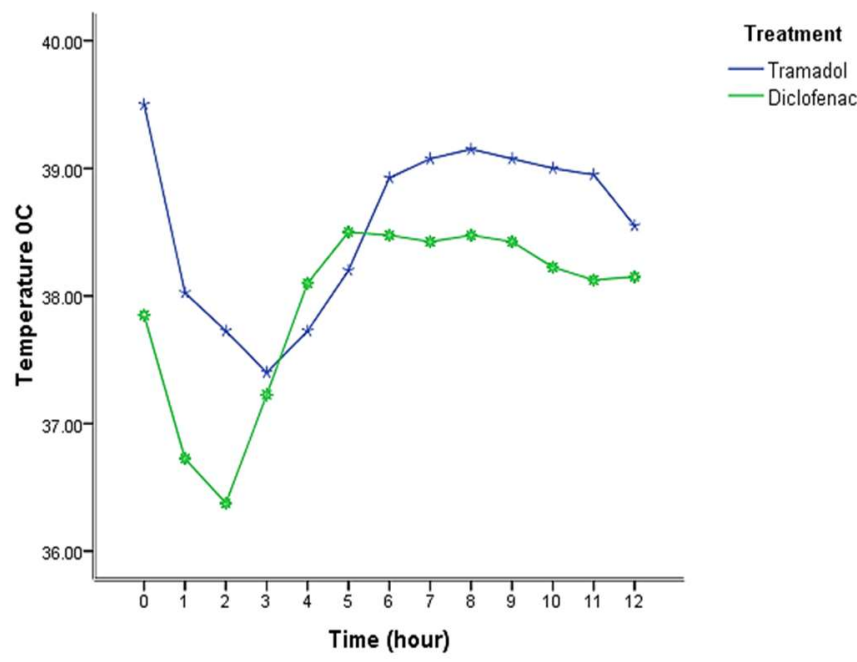

Figure 1: Comparison of rectal temperature reading (means $\pm \mathrm{SD}$ ) between goats receiving tramadol $(3 \mathrm{mg} / \mathrm{kg} \mathrm{BW}, \mathrm{IM})$ and goats receiving diclofenac sodium $(2.5 \mathrm{mg} / \mathrm{kg} \mathrm{IM})$ preoperatively, $\mathrm{n}=4$ in each group. There was no significant different between the groups at $\mathrm{p}>0.05$.

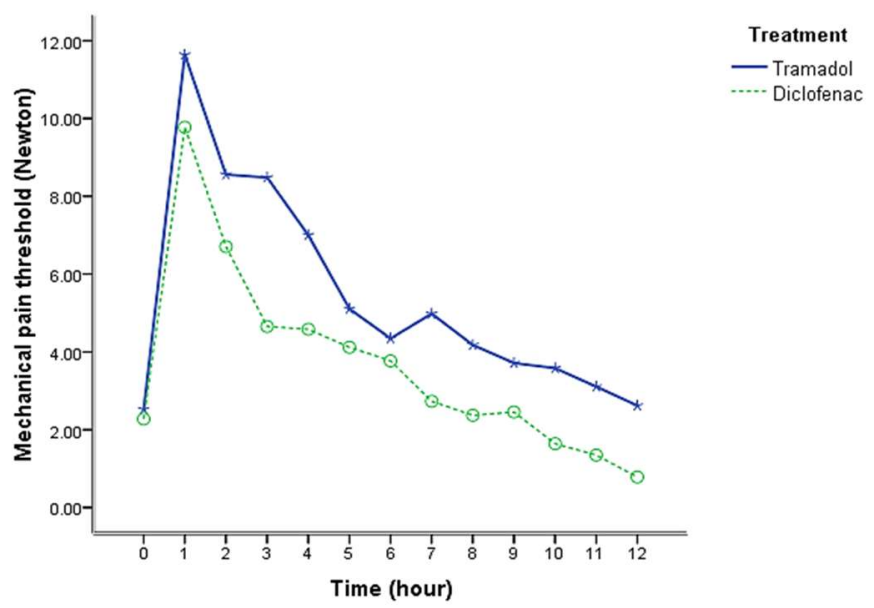

Figure 2: Comparison of analgesiometer pain threshold value (means $\pm \mathrm{SD}$ ) between goats receiving tramadol (3 mg/kg BW, IM) and the goats receiving diclofenac sodium $(2.5 \mathrm{mg} / \mathrm{kg} \mathrm{IM})$ preoperatively, $\mathrm{n}=4$ in each group. There was no significant difference between groups at $p>0.05$.

In addition, both groups treated with tramadol and diclofenac had a significant decrease in pain perception few hours post administration of the drugs. The differences in analgesiometer readings were widely variable in both groups over time. The tramadol and diclofenac sodium groups had an initial increased in the pain threshold of $12 \mathrm{~N}$ and $11 \mathrm{~N}$ at the first hour after surgery respectively $(p>0.05)$. Gradually, the threshold level decreases over the period of 12 hours (Figure 2). When their clinical and haematological parameters were evaluated, there were statistically significant 
differences in the values of the pulse rates (Figure 3), respiratory rates (Figure 4), red blood cell (Figure 5) and white blood cell (Figure 6) counts between the groups.

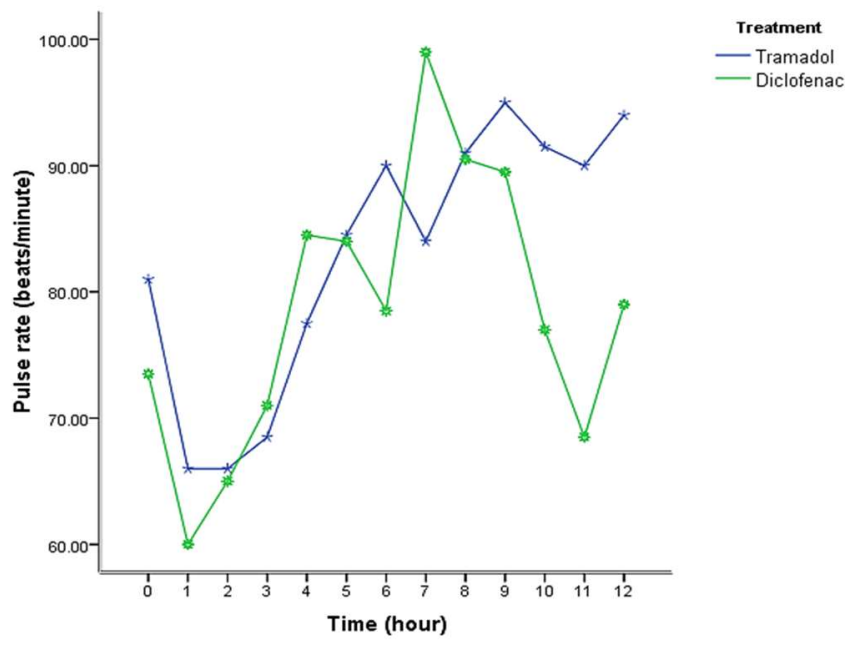

Figure 3: Comparison of pulse rates value (means $\pm \mathrm{SD}$ ) between goats receiving tramadol $(3 \mathrm{mg} / \mathrm{kg} \mathrm{BW}, \mathrm{IM})$ and goats receiving diclofenac sodium $(2.5 \mathrm{mg} / \mathrm{kg} \mathrm{IM})$ preoperatively, $\mathrm{n}=4$ in each group. There were significant differences between the groups at $6^{\text {th }}$, $7^{\text {th }}, 9^{\text {th }}, 10^{\text {th }}, 11^{\text {th }}$ and $12^{\text {th }}$ hours post drug administration $(p<0.05)$.

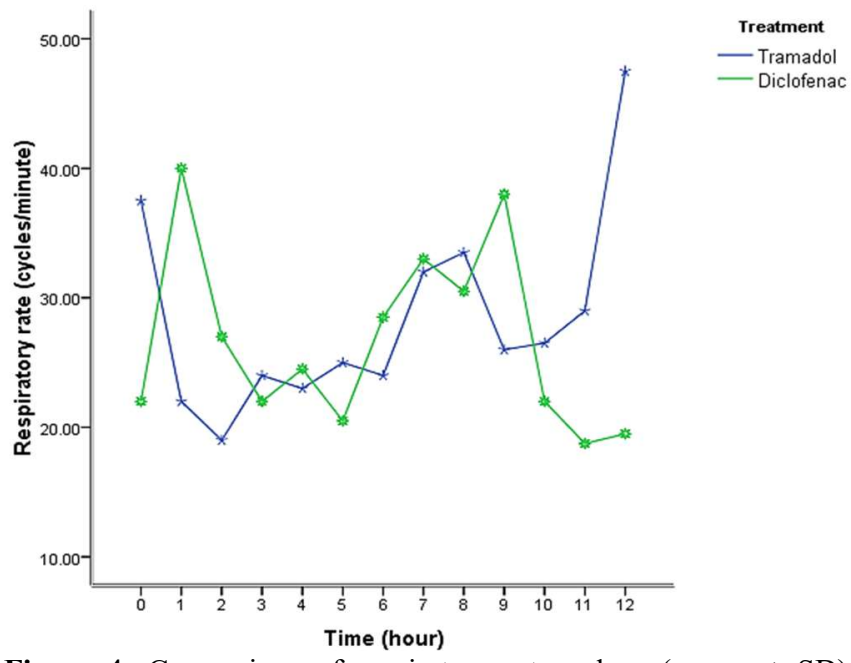

Figure 4: Comparison of respiratory rate values (means \pm SD) between goats receiving tramadol $(3 \mathrm{mg} / \mathrm{kg} \mathrm{BW}, \mathrm{IM})$ and goats receiving diclofenac sodium $(2.5 \mathrm{mg} / \mathrm{kg} \mathrm{IM})$ preoperatively, $\mathrm{n}=4$ in each group. There were significant differences between the groups at first two hours and at $9^{\text {th }}, 11^{\text {th }}$ and $12^{\text {th }}$ hours post drug administration $(\mathrm{p}<0.05)$.

\section{DISCUSSION}

Over three decades, the veterinary profession has witnessed a significant revolution in analgesic administration. Currently, several choices in different drugs for postoperative pain management are made available (Bateman et al., 2008). For a better and practical choice of analgesic drug, randomized blinded evaluation to compare different analgesic agents is essential. In general, NSAIDs are considered suitable analgesics for postoperative pain management in small animals, alone or in combination with opioids (Morgaz et al., 2013). Diclofenac provided a smooth and good analgesic effect during this study. Abu-Seida
(2012) reported an excellent analgesic effect using diclofenac in dogs undergoing ovariohysterectomy. Diclofenac was used to treat experimentally produced myositis in goats (Aktaruzzaman et al., 2008) and its significant effect on blood cell count subsided 72 hours post drug administration (Ahmad et al., 2013).

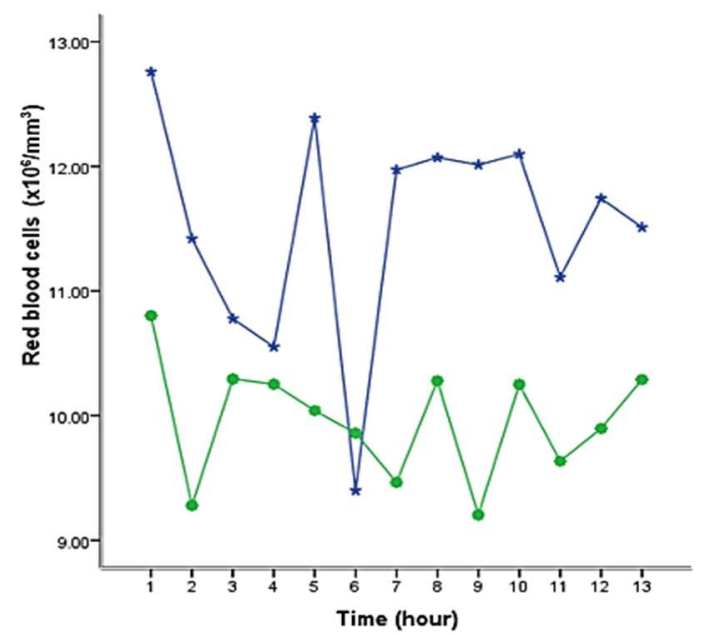
- Tramadol - Diclofenac

Figure 5: Comparison of red blood cell counts (means \pm SD) between goats receiving tramadol $(3 \mathrm{mg} / \mathrm{kg} \mathrm{BW}, \mathrm{IM})$ and goats receiving diclofenac sodium $(2.5 \mathrm{mg} / \mathrm{kg} \mathrm{IM})$ preoperatively, $\mathrm{n}=4$ in each group. The red blood cell counts significantly differ between the groups except at the $5^{\text {th }}$ hour post drug administration $(\mathrm{p}<0.05)$.

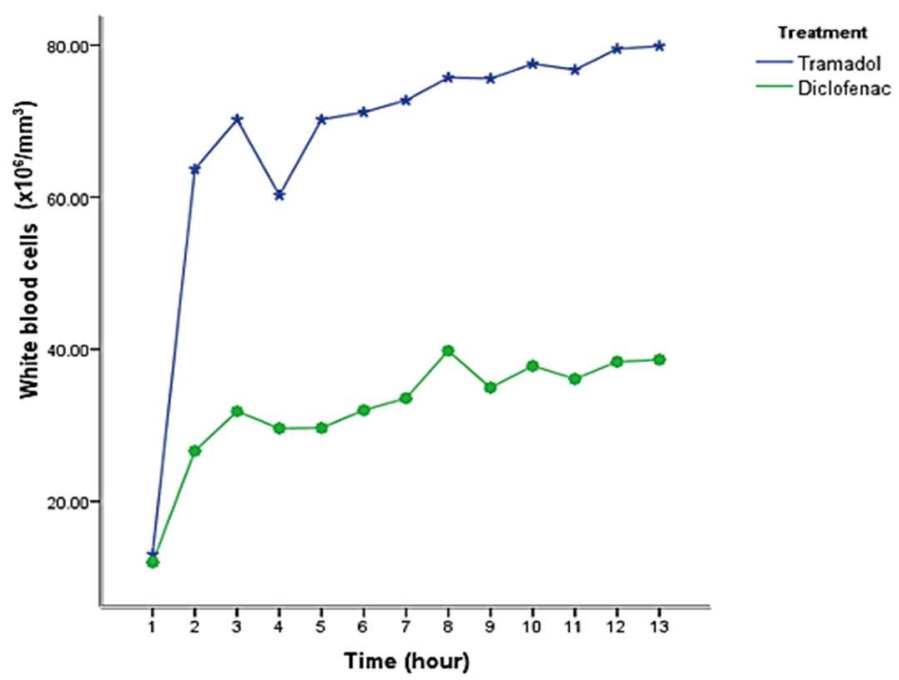

Figure 6: Comparison of white blood cell counts (means \pm SD) between goats receiving tramadol $(3 \mathrm{mg} / \mathrm{kg} \mathrm{BW}, \mathrm{IM})$ and goats receiving diclofenac sodium $(2.5 \mathrm{mg} / \mathrm{kg} \mathrm{IM})$ preoperatively, $\mathrm{n}=4$ in each group. There was significant increase in the white blood cell counts in the group treated with tramadol $(\mathrm{p}<0.05)$.

Physiologic indicators of acute pain in animals include increased heart rate, increased blood pressure, peripheral vasoconstriction and cardiac dysrhythmias (Buhari et al., 2012). In this study, other than the slight increase in pulse and respiratory rates observed among the goats treated with tramadol from eight hours after the drug administration pulse rates, respiratory rates, and rectal temperatures did not vary significantly between the groups. Similar observations were made following epidural administration of tramadol in dogs 
undergoing stifle surgery (Guedes et al., 2005). In horses that received epidural tramadol, good analgesia was achieved without significantly influencing the horses' behavioral and physiological parameters (Natalini and Robinson, 2000). Increase in the rectal temperature has been used as an indicator for postsurgical pain (Sanford et al., 2006; Landa 2012) due to the stimulation of autonomic sympathetic system trigger the releases of adrenaline elevates body temperature (Koknaroglu and Akunal, 2013). Okafor et al. (2014) reported the decreasing effect of NSAIDs on rectal temperature. They inhibit neurotransmitter that mitigates the release of adrenocorticotropic hormone from the hypothalamic pituitary system (Karanth et al., 2000). The slight increase in these two parameters could be due to shorter half-life of tramadol compared to that of diclofenac (Brogden, et al., 1980; McMillan et al., 2008), hence tramadol may be administered every 12 hours (Lamont and Mathews, 2007) at dose rate of $4 \mathrm{mg} / \mathrm{kg}$ in goats (de Sousa et al., 2008).

Increase in the number of white blood cells (WBC) observed in this study after tramadol administration was in agreement with what was reported earlier in rats (Aldiwan et al., 2015). A decrease in WBC was also published in the rabbit after tramadol administration (Aldiwan et al., 2015). Acute blood loss and surgical stress cause changes in both red and white blood cell counts (Hong, 2005). However, the variation in values of red blood cells and white blood cells between the groups fluctuated within the normal physiological limits and, therefore, has no clinical significance as far as the effects of the tramadol and diclofenac were concerned. Similar findings were also reported with epidural bupivacaine in goats and buffaloes (Singh et al., 2007; Singh, 1999). Bupivacaine share similar mechanism of action with lignocaine albeit the longer duration of effect over lignocaine, but both of them offered similar analgesic effect (Devi and Singh 2018). Similarly, in the present study, both groups treated with diclofenac and tramadol had an effective postoperative analgesia. The mechanical pain threshold values suggested a more uniform analgesia to painful stimuli. The pain score did not significantly differ between the tramadol and diclofenac groups at any time (figure 2). Therefore, analgesic effects of the drugs are likely to be present for at least 10 hours after administration; tramadol and diclofenac have variable halflife of 3-6 hours and 10-24 hours respectively (Brogden, et al., 1980; McMillan et al., 2008). In another study by Brondani et al. (2009), tramadol provided similar analgesic effect with NSAIDs in cats undergoing ovariohysterectomy. These therefore, suggested comparable postoperative analgesia from both drugs.

\section{Conclusion}

Based on the study design, the data suggest that pre-treatment with tramadol (3 $\mathrm{mg} / \mathrm{kg} \mathrm{IM})$ provided similar adequate postoperative analgesia as with diclofenac sodium $(2.5 \mathrm{mg} / \mathrm{kg}$ IM) following femoral diaphyseal fracture reduction-fixation in goats. Further studies, however, will be needed for more detailed information on the quality of analgesia of both drugs in goats.

\section{Conflict of Interest}

The authors declare that they do not have any conflict of interest.

\section{Author's Contribution}

BS designed the research and supervised the project, AJ, BZM and AS were involved in blood sample collection and parameter evaluation, $\mathrm{AN}$ and BHA, served as assistant surgeons and anaesthesiologist, respectively; SMI participated in the statistical analysis, literature and manuscript review.

\section{REFERENCES}

Abu-Seida A. M. A. (2012). Efficacy of Diclofenac Sodium, Either Alone or Together with Cefotaxime Sodium, for Control of Postoperative Pain, in Dogs Undergoing Ovariohysterectomy. Asian Journal of Animal and Veterinary Advances, 7 (2): 180-186.

Ahmad I., Qureshi T. A., Sadique U., Khan S. A., Ahmed S., Rehman Z. U., Bahadar S. and Mushtaq M. (2013). Hematological Effects of Diclofenac Sodium in Goat. The Journal of Animal and Plant Sciences, 23(1): 103-107.

Aktaruzzaman M., Alam J., Rahman A. and Hossain M. M. (2008). Clinico-Haematological Effect of Selected NSAID in The Treatment of Experimentally Produced Myositis in Goat. Baghdad Journal of Veterinary Medicine, 6(1): 99-102.

Al-Bulushi S., Shawaf T. and Al-Hasani A. (2017). Some hematological and biochemical parameters of different goat breeds in Sultanate of Oman "A preliminary study", Veterinary World, 10(4): 461466.

Aldiwan M. A., Alzobidy A. M. H. and Younis M. A. (2015). The effect of Tramadol on some blood and biochemical parameters of male rats (Rattus norvegicus). Baghdad Science Journal, 12(3), 496502.

Bateman S. W., Haldane S. and Stephens J. A. (2008). Comparison of the analgesic efficacy of hydromorphone and oxymorphone in dogs and cats: a randomized blinded study. Veterinary Anaesthesia and Analgesia, 35, 341-347.

Booth D. M. (2001). The Analgesic, Antipyretic, Antiinflammatory Drugs. In: Veterinary Pharmacology and Therapeutics, $8^{\text {th }}$ Edition., The Iowa State University Press, Ames, IA., USA., 432-449.

Brogden R. N., Heel, R. C. and Pakes, G. E. (1980). Diclofenac sodium: A Review of its Pharmacological Properties and Therapeutic Use in Rheumatic Diseases and Pain of Varying Origin. 2448.

Brondani J. T., Loureiro luna S. P., Beier S. L., Minto B. W. and Padovani C. R. (2009). Analgesic efficacy of perioperative use of vedaprofen, tramadol or their combination in cats undergoing ovariohysterectomy. Journal of Feline Medicine and Surgery, 11 (6): 420-429. 
Buhari S., Kalthum H., Goh Y. M., Noordin M. M. and SiewHua G. (2012). Subcutaneous Administration of Tramadol after Elective Surgery Is as Effective as Intravenous Administration in Relieving Acute Pain and Inflammation in Dogs. The Scientific World Journal, 1-7.

Buhagiar L., Cassar O. A., Brincat M. P., Buttigieg G. G., Inglott A. S., Adami M. Z. and Azzopardi L. M. (2011). Predictors of post-caesarean section pain and analgesic consumption. Journal of anaesthesiology, clinical pharmacology, 27(2), 185191.

Buvanendran A., Kroin, J. S. and Tuman, K. J. (2003). Effects of Perioperative Administration of a Selective Cyclooxygenase 2 Inhibitor on Pain Management and Recovery of Function after Knee Replacement: A Randomized Control Trial, 290: 2411-2418.

De Sousa A. B., Santos A. C. D., Schramm S. G., Porta V., Górniak S. L., Florio J. C. H. and de Souza S. (2008). Pharmacokinetics of tramadol and Odesmethyltramadol in goats after intravenous and oral administration. Journal of Veterinary Pharmacology and Therapeutics, 31(1): 45-51.

Devi N. S. and Singh K. N. (2018). Comparison of lignocaine $2 \%$ with adrenaline and a mixture of bupivacaine $0.5 \%$ plus lignocaine $2 \%$ with hyaluronidase for peribulbar block analgesia, Journal of Medical Society, 32(3): 190-194.

Guedes A. G. P., Natalini, C. C., Robinson E. P., Alves S. D. L. and Oliveira S. T. (2005). Epidural administration of tramadol as an analgesic technique in dogs submitted to stifle surgery. The International Journal of Applied Research in Veterinary Medicine, 3(4): 352-359.

Haussler K. K., Hill A. E., Frisbie D. D. and McIlwraith C. W. (2007). Determination and use of mechanical nociceptive thresholds of the thoracic limb to assess pain associated with induced osteoarthritis of the middle carpal joint in horses. American Journal of Veterinary Research, 68(11), 1167-1176.

Hellyer P., Rodan I., Brunt J., Dwning R., Hagedorn J. E. and Robertson S. A. (2007). Pain management guidelines for dogs and cats. Journal of Feline Medicine and Surgery, 9(6): 466-480.

Hong Y. (2005). The Effect of Preoperative Ketorolac on WBC Response and Pain in Laparoscopic Surgery for Endometriosis. Yonsei Medical Journal, 46(6): 812-817.

Katz J., Kavanagh B. P..and Sandler A. N. (1992). Preemptive analgesia. Clinical evidence of neuroplasticity contributing to postoperative pain. Anesthesiology, 77: 439-446.

Kissin I. (2000). Preemptive analgesia. Anesthesiology, 93: 1138-1143.

Koknaroglu H. and Akunal T. (2013). Animal welfare: an animal science approach. Meat Science. 95:821827.

KuKanich B. and Papich, M. G. (2004). Pharmacokinetics of tramadol and the metabolite O-desmethyltramadol in dogs. Journal of Veterinary Pharmacology and Therapeutics, 27(4): 239-246.

Lamont L. A. and Mathews K. A. (2007). Opioids, nonsteroidal anti-inflammatories and analgesic adjuvants. Lumb and Jone. Veterinary Anaesthesia and Analgesia. Blackwell Publishing, Iowa, 241272.

Landa L. (2012). Pain in domestic animals and how to assess it: a review. Veterinarni Medicina. 57:85-192.

Laredo F. G., Belda E., Murciano J., Escobar M., Navarro A., Robinson K. J. and Jones R. S. (2004). Comparison of the analgesic effects of meloxicam and carprofen administered preoperatively to dogs undergoing orthopaedic surgery. Veterinary Record, 155: 667671.

Lascelles B. D. X. (1999). Preoperative analgesia-opioids and NSAIDs. Waltham Focus ${ }^{\circledR}, 9(4)$ : 2-9.

Lascelles B. D. X. and Mair T. S. (2001). Drugs Used in the Treatment of Disorders of the Musculoskeletal System and Joints. In: The Veterinary Formulary, $5^{\text {th }}$ Edition., Pharmaceutical Press, London, UK., 469-487.

Lee L. (2011). Pain management via systemic approach beyond opioids. In: Proceedings of the 36th World Small Animal Veterinary Congress. Jeju, Korea. www.wsava2011.org.

Mastrocinque S. and Fantoni, D. T. (2003). A comparison of preoperative tramadol and morphine for the control of early postoperative pain in canine ovariohysterectomy. Veterinary Anaesthesia and Analgesia, 30(4): 220-228.

McMillan C. J., Livingston A., Clark C. R., Dowling P. M., Taylor S. M., Duke T. and Terlinden R. (2008). Pharmacokinetics of intravenous tramadol in dogs. Canadian Journal of Veterinary Research, 72(4): 325-331.

Moak P., Hosgood G., Rowe E. and Lemke K. A. (2010). Evaluation of intra-articular and subcutaneous administration of meloxicam for postoperative analgesia following stifle surgery in dogs. Veterinary and Comparative Orthopaedics and Traumatology, 24(1), 32-38.

Morgaz J., Navarrete R., Munoz-Rascon P., Dominguez J. M., Fernandez-Sarmiento J. A., GomezVillamandos R. J. and Granados M. M. (2013). Postoperative analgesic effects of dexketoprofen, buprenorphine and tramadol in dogs undergoing ovariohysterectomy. Research in Veterinary Science, 95: 278-282.

Natalini C. C. and Robinson E. P. (2000). "Evaluation of the analgesic effects of epidurally administered morphine, alfentanil, butorphanol, tramadol in horses," American Journal of Veterinary Research, 61(12): 1579-1586.

Okafor R. O. S., Remi-Adewunmi B. D., Fadason S. T., Ayo J. O. and Muhammed S. M. (2014). Evaluation of the effect of piroxicam and ascorbic acid combination on live weight and rectal temperature of savannah brown goats during post-operative pain management, Journal of Applied Animal Research, 43(4): 439-444. 
Ortega M. and Cruz I. (2011). Evaluation of a constant rate infusion of lidocaine for balanced anesthesia in dogs undergoing surgery, The Canadian Veterinary Journal, 52(8):856-60.

Polianskis R., Graven-Nielsen T. and Arendt-Nielsen L. (2002). Spatial and temporal aspects of deep tissue pain assessed by cuff algometry. Pain, 100(1), 1926.

Pollock R. E., Lotzova E. and Stanford S. D. (1991). Mechanism of surgical stress impairment of human perioperative natural killer cell cytotoxicity. Archive of Surgery, 126(3), 338-342.

Reid J., Nolan A. M., Hughes J. M. L., Lascelles D., Pawson P. and Scott E. M. (2007). Development of the shortform Glasgow Composite Measure Pain Scale (CMPS-SF) and derivation of an analgesic intervention score. Animal Welfare-Potters Bar Then Wheathampstead, 16:97.

Sanford J., Ewbank R., Molony V., Tavenor W.

D. and Uvarov O. (2006). Guidelines for the recognition and assessment of pain in animals. Veterinary Research Communication. 31:801-808.

Singh K., Kinjavdekar P., Amarpal A. H. P., Gopinathan A., Singh G. R., Pawde A. M. and Pratap K. (2007). Comparison of the analgesic, clinicophysiological and hematobiochemical effects of epidural bupivacaine in healthy and uremic goats. Small Ruminant Research. 71: 13-20.
Singh P. (1999). Xylazine, ketamine, lignocaine and their combinations for lumbar epidural analgesia in buffalo calves. MVSc Thesis, submitted to Deemed University, IVRI, Izatnagar.

Slingsby L. (2010). Considerations for prospective studies in animal analgesia. Veterinary Anaesthia and Analgesia, 37: 303-305.

Tesfaye W., Awukew A. and Thomas N. (2017). Postoperative Pain and its Management in Local Breed Sheep: A Review. International Journal of Advanced Research in Biological Sciences. 4: 3.

Wagner A. E., Gaynor J. S. and Muir W. W. (2002). Handbook of veterinary pain management. 9: 164183.

Waterman A. E. and Kalthum W. (1989). Pharmacokinetics of Intramuscularly Administered Pethidine in Dogs and the Influence of Anaesthesia and Surgery. The Veterinary Record, 124(12): 293-6.

Witmer D., Marshall S. T., Browner B. D., Beauchamp R. D., Evers B. M., Kenneth M. and Sabiston L. (2016). "Emergency care of musculoskeletal injuries". In Courtney Textbook of Surgery (20th edition). Elsevier. 462-504. 